\title{
Article \\ Proposal of Methodology for Evaluation of a Vertical Shanty Building in Beira, Mozambique
}

\author{
Michael M. Santos ${ }^{1, * \mathbb{C}}$, João C. G. Lanzinha ${ }^{1} \mathbb{D}$ and Ana Vaz Ferreira ${ }^{2} \mathbb{(}$ \\ 1 Centre of Materials and Building Technologies (C-MADE/UBI), Department of Civil Engineering and Architecture, \\ University of Beira Interior (UBI), 6201-001 Covilhã, Portugal; jcgl@ubi.pt \\ 2 Civil Engineering Department, Polytechnic Institute of Castelo Branco, 6000-084 Castelo Branco, Portugal; \\ vaz.ferreira@ipcb.pt \\ * Correspondence: michaelmendessantos@gmail.com
}

Citation: Santos, M.M.; Lanzinha, J.C.G.; Vaz Ferreira, A. Proposal of Methodology for Evaluation of a Vertical Shanty Building in Beira, Mozambique. CivilEng 2021, 2, 35-47. https://doi.org/10.3390/ civileng2010003

Received: 19 October 2020 Accepted: 31 December 2020 Published: 5 January 2021

Publisher's Note: MDPI stays neutral with regard to jurisdictional clai$\mathrm{ms}$ in published maps and institutional affiliations.

Copyright: (C) 2021 by the authors. Licensee MDPI, Basel, Switzerland. This article is an open access article distributed under the terms and conditions of the Creative Commons Attribution (CC BY) license (https:// creativecommons.org/licenses/by/ $4.0 /)$.

\begin{abstract}
Emerging economies are in an almost winless situation: they would benefit from improving the extremely poor economic situation, making them self-reliant and economically productive. However, the poor fight for daily survival and, therefore, cannot afford to improve themselves. This article describes the state of the "Grande Hotel" in the city of Beira, Mozambique, built-in Portuguese colonial times, a real vertical shanty building that is occupied by approximately 1000 inhabitants trapped in poverty. To carry out any constructive intervention in a building or an urban complex, it is necessary to carry out a rehabilitation project that is developed based on a diagnosis of the building understudy, its main deteriorations, the causes, mechanisms of action, evolution, and possible treatments to be used for its repair. Analysis methods are necessary for the conservation of buildings since trying to stop, or correct buildings' deterioration without a diagnosis of their problems or a prognosis on their evolution is a risky procedure with a high percentage of failure chances. The use of an appropriate methodology for diagnosing the damage present in the "Grande Hotel" and its prediction of evolution and development should directly impact a better quality of rehabilitation projects in the neighborhood where the building is located.
\end{abstract}

Keywords: colonial heritage; inspection of buildings; rehabilitation of buildings; pathologies; methodology

\section{Introduction}

Located on the eastern coast of Africa, Mozambique is about $2770 \mathrm{~km}$ long along coastline bathed by the Indian Ocean and a predominance of the humid tropical climate [1]. It is important to remember that the largest number of populous and essential urban centers of this country lies along the coastline, as is Beira's case. Beira has about 431,583 residents, standing out as the third most populous urban center in Mozambique [2].

Many African countries have surpassed their colonial past. They are currently in the process of expanding their economies by providing resources to other countries. This creates instability between and within countries [3]. It is likely to widen the gap between the poor and wealthy class, thus possibly creating social friction, agitation, and an unsafe environment to live in. If the poor could improve their living conditions on their own, it could benefit the country and the economy as a whole [4]. This paper describes a diagnostic methodology of the damages present in the "Grande Hotel" in the "Ponta Gêa" neighborhood in the city of Beira, Mozambique. The degradation of old residential buildings, inhabited or not, especially in historical centers and central urban areas, is a rather important issue worldwide [5].

\section{The "Grande Hotel"}

In this, an article review of different studies conducted by several authors is made. The Grande Hotel is today a dilapidated building occupied by low-income people from 
Beira. It is a place of anarchy and survival. To have a clear understanding, it essential to understand the historical and functional context of the building.

\subsection{A Short History of Beira}

From the European point of view, Mozambique was discovered by Vasco da Gama in 1492 and later claimed by the Portuguese as a colony until 1975 [6]. The port city and the capital Maputo were created on Mozambique's southern tip, now with more than 1 million inhabitants. Beira's city has 431,583 inhabitants in the center in the center. It transformed the second largest city and main port that serves Austral Africa to send its natural resources abroad. After the Portuguese withdrew from the city, the native Mozambicans who hoped to improve their living standards settled in the city. The friction between these two worlds is visible in the way the poor and prosperous life. This is the situation of the "Grande Hotel" of Beira [2].

\subsection{The "Grande Hotel" before}

In 1953, Artur Brandão, a good friend of Salazar's Estado Novo Portuguese regime and director of the Mozambique Company that once colonized Beira's interior, commissioned architect Francisco de Castro to build the Grande Hotel (Figure 1). It was intended to become the main part of the success of Estado Novo politics at that time. It was intended to provide 5-star accommodation for business partners, influential people, wealthy tourists from Rhodesia, South Africa, and the Portuguese colonial empire. The hotel operated for only eight years. According to the client's ideals, the total construction costs exceeded the budget by $300 \%$ (original cost 90,000\$00 Portuguese escudos, estimated: 30,000\$00 [7]), but money was well spent. With 116 rooms and a surface area of $21,000 \mathrm{~m}^{2}$, it was never profitable even by the most optimistic estimates. Until Mozambique's independence, the swimming pool was open to the neighborhood inhabitants. The building was used for conferences only twice. Some argue that failure was not obtaining a casino license [7]. The political system believed it was immoral to play in Portuguese colonies [8].

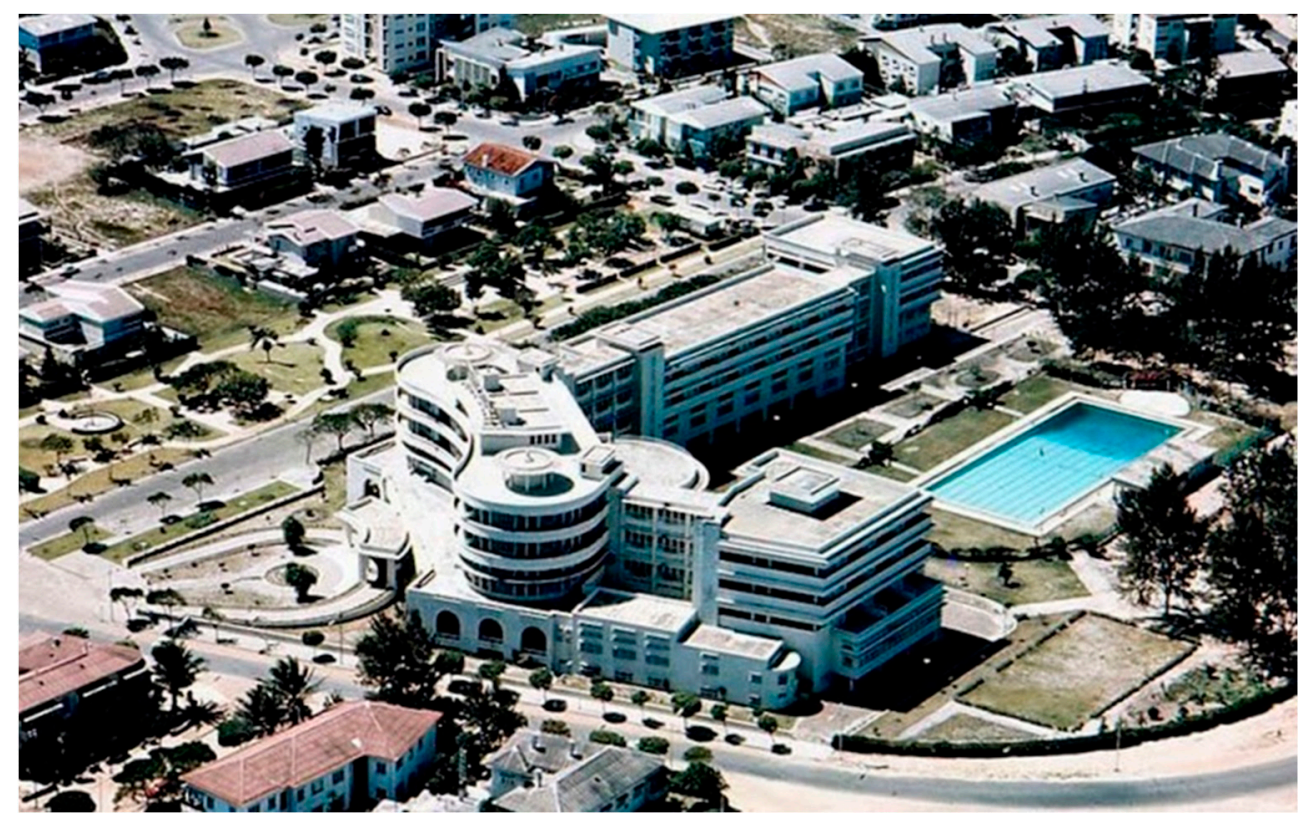

Figure 1. “Grande Hotel” da Beira, 1960s [7].

After the Portuguese Revolution of 1974, Mozambique became an independent state with joint growing pains. The communist party FRELIMO (Mozambique Liberation Front) came to power and used the "Grande Hotel" as a base to establish the communist state in the region. In the Mozambican Civil War (1977-1992), the hotel became a military base. In 1981, the city became part of a neutral zone controlled by the Zimbabwe Defense Force 
to secure Zimbabwe's exports to the Border Corridor. The provision of security and aid has attracted refugees from the countryside [8]. The "Grande Hotel" was transformed into a refugee camp, and the soldiers were transferred to the battlefield. Since 1992, Mozambique has experienced stability and peace. Today, the port of Beira is rehabilitated. It is undergoing an economic expansion due to the transit of minerals to Asia [8].

\subsection{The "Grande Hotel" of Beira Now}

Today the "Grande Hotel" accommodates about 1000 inhabitants. It acts as an informal neighborhood by itself with some street vendor stalls and internal squares. Large families of up to nine people populate hotel rooms and built-in shelters. They pay no rent and cannot claim the property right. The building's space and architecture do not meet the needs and do not offer habitability or structural security. Although the neighborhood secretary who also lives in the "Grande Hotel", is seen as the unofficial supervisor, he does not have the power of other municipal secretaries in more prosperous communities in Mozambique. The only common rule of the "Grande Hotel" is to respect each other; then, the "Grande Hotel" is open to those who need shelter [9].

There is no maintenance of the construction or public spaces. Garbage is dumped everywhere and is never cleaned. Damaged roofs and frames have no glass. Elevator-free wells are now openly accessible holes that are dangerous after dark for young and old. The garden gives space to Mozambique's first Olympic swimming pool. It contains highly polluted water and is used for fishing, consumption, washing, and public washbasin like so many other places. According to the local Red Cross, there is a high risk of cholera, diarrhea, malaria, HIV, and others [10].

Most of the inhabitants of the "Grande Hotel" work in the informal economic sector, excludes them from participation in Beira's society and economic community. The formal economy is growing because of the booming transit at the port and puts the informal economy under pressure. It becomes even more difficult for the "Grande Hotel" inhabitants to make ends meet for basic life. The building was gradually stripped of all materials that could be sold for some food, such as plumbing, wiring, and parquet pavement. Thus, poverty made life even more difficult at the Hotel Grande is where crime thrives and where the police have no authority [10].

This is a dark image (Figure 2); however, it is a fascinating building as a shelter for a dynamic society from which one cannot escape and has already delivered its third generation of inhabitants. The architecture and its users over time reflect Mozambique's struggling history.

The municipality would like to intervene but are not the legal owners, nor are they responsible for the "Grande Hotel," one of Mozambique's few properties not owned by the state. Officially still belongs to "Grupo Entroposto S.A.," based in Portugal, which is the continuation of the Company of Mozambique. There are no local funds for the building's refurbishment, and the poor collaboration of local parties with the national government blocks the way to national funds [11]. No private investor is willing to participate in this risky project. Currently, the municipality wants to relocate the current inhabitants to neighborhoods on the city's outskirts and demolish the "Grande Hotel" to clear the land for refurbishment as a place of commercial and tourist activities [12].

However, we have a historical heritage value, consideration of heritage values is an integral part of preservation decision making. For several decades, aesthetic and historical associations have traditionally dominated the work of preservation, and decision-making about values has typically been limited to specialists, following a curatorial approach. These practices' narrowness forced the field to consider a broader range of values from a broader and more inclusive set of stakeholders. Heritage is increasingly understood as a social construction. That is, it results from specific social processes of time and place. Thus, preservation works to conserve places and objects whose fabric is not inherently valuable but rather valued by its associations, which are complex, variable, and dynamic. Despite 
their importance established at the heart of decision-making on preservation, values are difficult to define as the qualities attributed to places and objects [13].

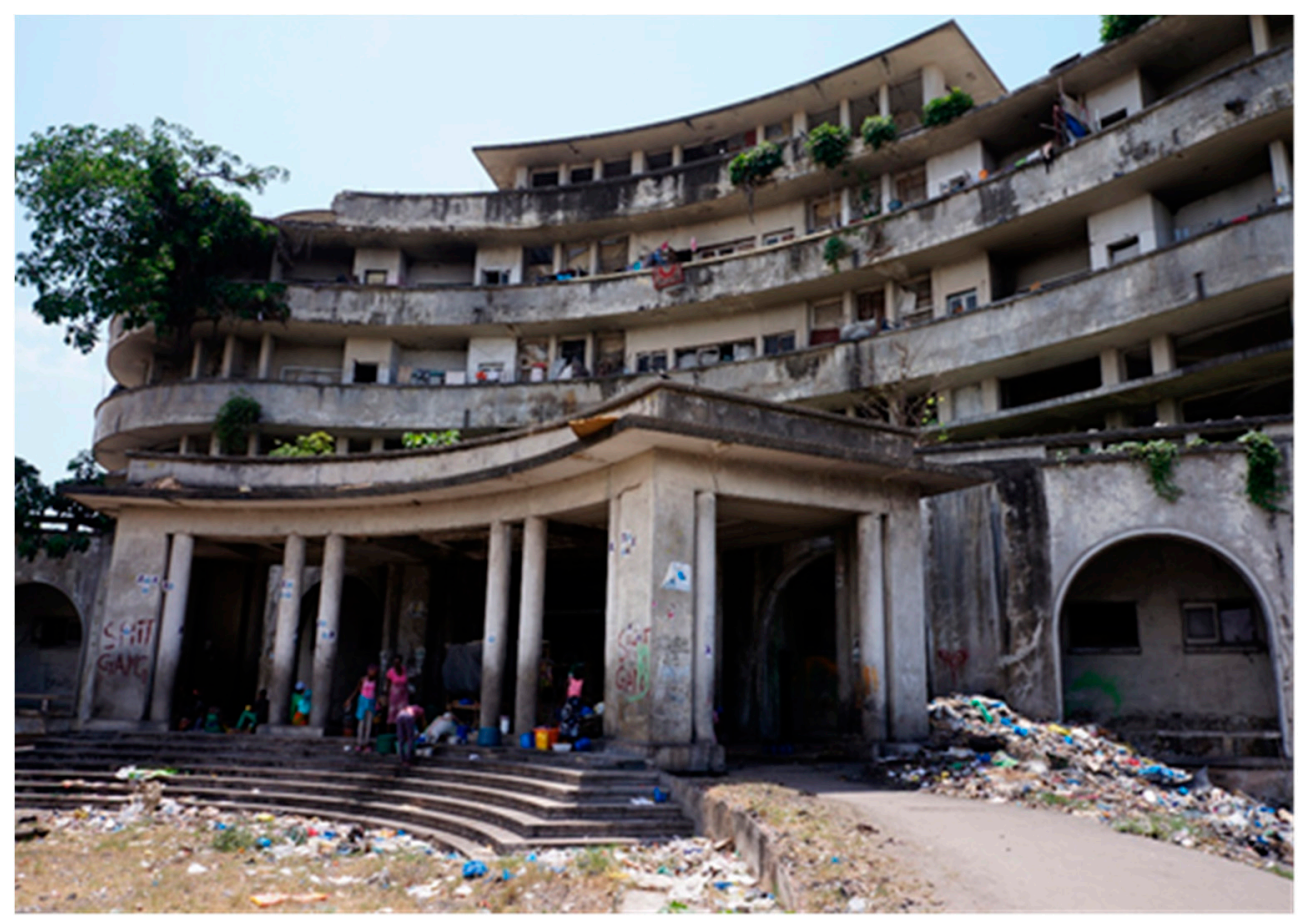

Figure 2. "Grande Hotel" of Beira, current state (December 2019).

This building, modern architecture was a way to fight against the totalitarian regime of the Estado Novo de Salazar, so it was in Lusophone Africa that it is implanted and developed. The new generation of Portuguese architects took these territories as a promising laboratory for modern exploration. Its development pillar was based in part on the Brazilian vocabulary: the adaptation of form to place, the integration of the arts, and their plasticity [14].

Designing with the climate, investigating the elements that compose it and how they can condition as architectural forms, solving these countries' needs, was the main objective of these architects. In Beira, these principles are visible both in architecture and urbanism, according to the Modern Movement's formal, technological, and ideological assumptions [15].

\section{Diagnostic Methodology}

To carry out any significant intervention in a building, it is necessary to carry out a rehabilitation project that develops from a previous diagnosis to value the structure's potential, which will undoubtedly directly impact the work economy.

Analysis methods are a primary tool for the conservation of buildings. Trying to stop or correct buildings' deterioration without a diagnosis of their problems or a prognosis on their evolution is a risk with a high percentage of failure chances. In case of partial or emergency reparations, inspection is based on a well-established analysis method and concepts. All conservation actions should include the set of factors that act on the construction's life, and nothing should be improvised or approached superficially or routinely [16].

The use of an appropriate methodology for the diagnosis of damage in a building, as well as its prediction of evolution and development, should have a direct impact on a better quality of the rehabilitation projects to be carried out, as well as on the successful results, from a scientific, technical, and economic point of view, on the research that is necessary for these purposes [17]. 
Currently, due to several factors, diagnostic studies that are performed are not always performed most efficiently. Sometimes unnecessary testing is done, or the sampling plan is too abundant or insufficient without responding to a scientifically justified analysis, which undoubtedly impacts the quality of projects that use these reports as a preliminary phase. Thus, it is essential to diagnose the building of the "Grande Hotel" of the Beira, considering the particularities it presents [18]. In diagnosing and managing construction is important to design an appropriate maintenance strategy for each building component. An appropriate maintenance strategy can be crucial to meet requirements based on local standards and guidelines [19].

\section{The Pathological Process: Its Analysis}

The encounter with a pathological process aims at its solution, which goes through the repair to return to its initial purpose. It is necessary to know its process, origin, causes, evolution, symptoms, and current state. This set of aspects of the problem must be grouped sequentially to obtain pathological processing. In a pathological process, three well-defined parts can be distinguished, the origin, evolution, and the result, so that, for its study, this path must be crossed inversely. Therefore, it is necessary to begin by observing the result of the lesion, the symptom, to reach its origin, to the cause, following its evolution [16].

This analysis should be methodical and thorough. Therefore, it is necessary to adopt systematic observation and data collection methods to limit possible pre-conceived ideas, i.e., to contain professional intuition that can be common and useful in some cases but extremely dangerous in others [20].

Considering the above, a methodology is developed for the diagnosis of buildings whose fundamental premises will be as follows:

- Classification and characterization of construction typologies.

- Identification of the damage associated with each constituent element.

- Identification of deterioration in the junction points between the elements.

- Determination of the origin evolution and current state of the different pathological states.

As a result of the assumptions defined earlier, we can define the schema presented in Figure 3.

In the initial inspection phase, the objective is to inspect the building to define the strategies for carrying out the diagnosis. The recognition of the environment in which the building is located, and the determination of its fundamental characteristics are the key points of this phase of the diagnostic work $[16,17]$.

The pathologies survey aims to seek the presence of damages that manifest themselves as symptoms of the pathological process and from which it is possible to know it. The first thing is to detect the damages, identify them, and independent of the different damages and pathological processes, to follow them correctly, primarily because of their possible relationship [21].

This phase concludes with the preparation of the survey of the damage, which will imply a repeated number of visits and the use of a camera that allows accurate capture of the damages at the time of inventory. In this way, a series of physical data can be obtained to facilitate understanding of the process. The data are indicated: the type of damage, description, possible causes, affected materials, damaged building elements, location of injuries, the level of exposure of the point of onset of the symptom about the street level, and proximity to other buildings.

Within the Methodology framework, two documents will be prepared to facilitate the work in this vital phase and not leave to improvise the tasks to be carried out during its performance: factsheets and general procedures for carrying out inspections $[15,17]$.

Subsequently, in the testing phase, this is carried out to rapidly evaluate the most critical points of the site to determine whether they need to be intervened urgently, for this purpose, simple measuring equipment or samples of materials will be used, such as 
extractions of carrots to know how an element that cannot be observed with the naked eye is composed, among other tests.

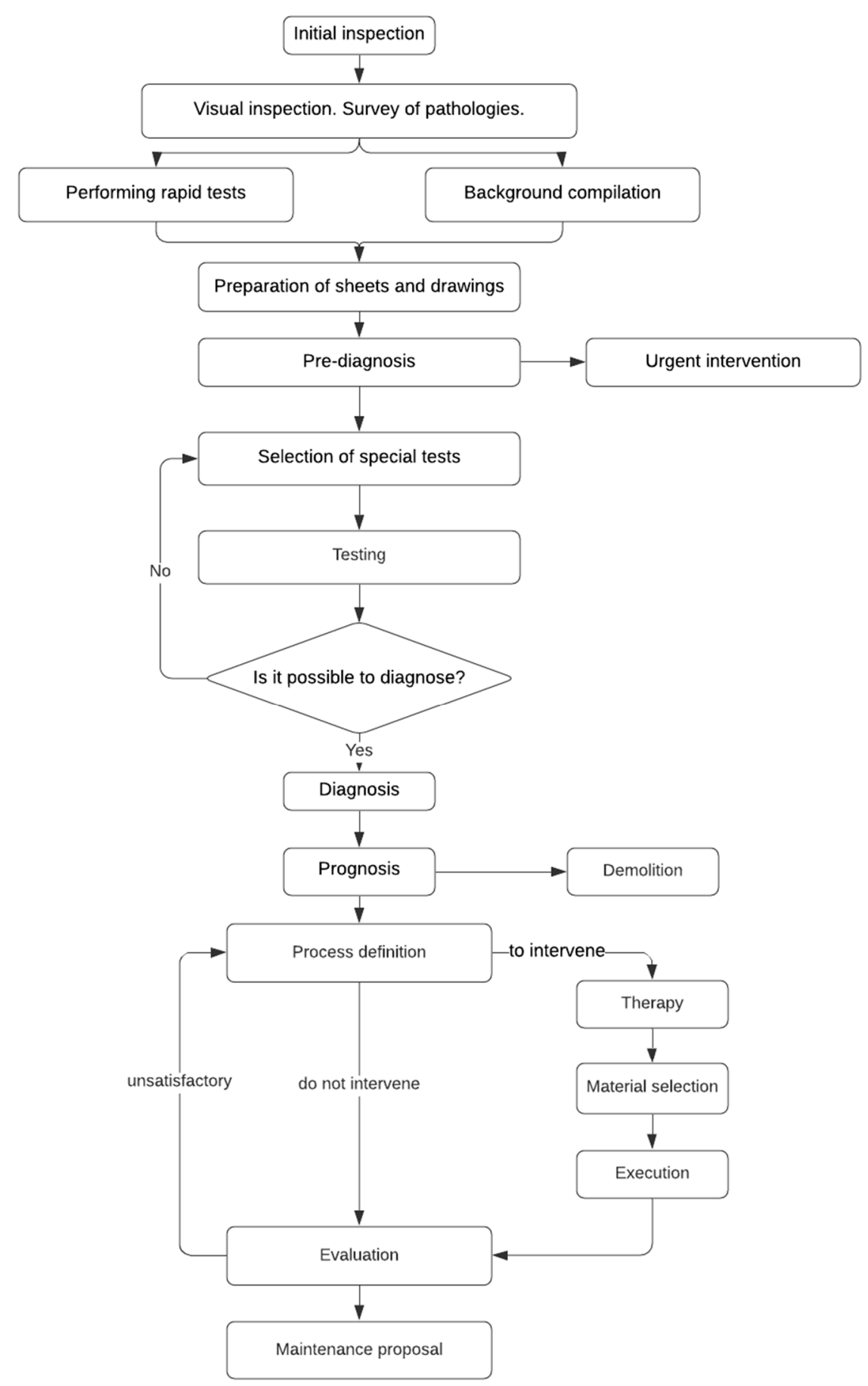

Figure 3. Methodology for diagnosis [21].

As a component of the methodology, the tests that should be performed must be identified during the diagnostic phase to support the equipment and type necessary for it, depending on the type of material that exists and the type of damage studied in each case [22].

At the same time, the reconstruction of demolished elements and parts, once these damages have been identified, can be conducted according to available sources that allows its identification. 
This will involve trying to obtain all kinds of graphic or written documentation about the building and even interviews with the inhabitants, users of the building or people of the neighborhood to know more details that are not reflected in the documentation: plans, photographs, previous diagnostic reports, demolition orders, date of appearance or periodicity of some damages, uses of the building, date of construction, system, and details of construction or pollution level of the construction environment, etc.

To facilitate the work to be carried out by the diagnostic team at this stage, the following documents will be prepared within the methodology framework: background research procedures and guidance for conducting interviews [16].

Specify the files or sources in which documents from this area of the city can usually be found and how to inspect them. Both are precisely guiding the tasks to be carried out to ensure the success of this vital phase.

Preparation of sheets and drawings must collect all the information obtained in the previous phases and are particularly important because they can be used for inspections in the future. To elaborate the drawings, it is recommended that they be elaborated at scale: plants, elevations cuts, and construction details.

Costs should also be observed at the scale of the deterioration observed at the inspection time as accurately as possible, representing the affected zone in each case.

Pre-diagnosis is a type of conclusion that can be achieved with the data obtained so far. It is like establishing hypotheses that will be tested in the next steps of this Methodology.

If it is only possible to implement the intervention proposal with pre-diagnosis, the intermediate steps will be ignored.

In the selection phase of specific tests, it will be crucial to train the teams that will carry out the inspections in order its correct application and accuracy of results obtained. In any case, the interpretation of these data will be vital to obtain precise conclusions after the inspection carried out.

Non-destructive testing should be a priority to affect as little as possible of the building under study. Where destructive testing is required, the most trained personnel shall design the sampling plan to prevent further damage to the structure and make research as economical as possible.

Also, in this case, as a component of the methodology, the diagnostic team is recommended the tests that can be done at this stage to facilitate the work of selecting them according to the type of material existing and logic of the damage to be studied in each case.

Performing the diagnosis, once the direct collection of data has been completed, and having the results of possible laboratory tests, can start the reconstruction of the facts, that is, try to know how the pathological process developed, what has been its origin and its causes, what its evolution and its current state.

At this stage, conclusions should be drawn for further actions involving the repair of the building. This analysis should include the following aspects: causes that led to the process, distinguishing between direct and indirect, with an accurate description of each of them and explanation of their relationship, both of various direct causes and of possible indirect ones that have acted together; the evolution of the pathological process, indicating its times, its possible periodicity, transformation or branching into new pathological processes; mechanisms of action, indicating the causes that motivated mainly or secondarily the current state of the studied element: current state of the situation of the process, its possible validity or its disappearance and the damages to which it gave rise and that constitute the perceptible symptoms of the process [23].

In the following forecasting and prognosis phase, the diagnostic team should rely on the diagnosis to prevent the damage's evolution and guide its correct treatment at a later stage.

A good prognosis should be based on the pathological process's diagnosis and the building's knowledge about its evolution. 
As a result, a set of different interventions at different levels can be defined to recover the building or a part of it due to a pathological problem. When the prognosis is not favorable, the building or element studied will be demolished.

As a final objective, the diagnosis allows arriving at proposals for constructive intervention that, as has already been said, will aim the restore the initial conditions and performance of the whole building and it components.

Rehabilitation strategies will depend on your knowledge of the building, its component materials, etc. It may or may not be known, in which case it will be necessary to investigate to ensure compatibility between what already exists and the technique to be used for its repair.

It should refer to both cause and effect, recalling the preference for the elimination of the cause. Cases of indirect causes can sometimes be practiced in general, so different cases should be considered.

If it is defective material, whether, by an error in its selection or by manufacture by default, it should be examined whether it is possible to replace it or whether, on the contrary, its physical or chemical treatment is better suited to give it the necessary properties.

When you are in the presence of a problem of constructive detail, either by a design defect or by the error in execution, the possibility of changing this according to the addition of new construction elements that correct the defect may be considered [23].

In slight, indirect causes are almost always easy to correct, either for one reason or another of the above mentioned.

Direct causes, on the other hand, are often more challenging to remove, especially when it comes to air agents or pollutants.

If mechanical causes are discussed, predictable stresses or loads can be triggered by eliminating or limiting them. Some steps can be taken to disappear or reduce, for example, limiting warehouse overloads or user-caused overloads.

The case of friction on the floors is virtually impossible to avoid unless the property is modified.

The physical causes are too complex to eliminate, so you should resort to the physical or chemical protection of the elements against them, including rain, wind, temperatures, etc.

Chemical causes are also complicated to eliminate specially when they are caused by pollutants in the atmosphere. In such cases, protection of the material or element should also be required.

If the problem is material interaction, it can be solved by placing barriers between them. The same will happen when the origin of the chemical is in animals or plants. In this case, the action must be supported by maintenance.

In general, most direct causes can be solved with protections that prevent physical, chemical, or mechanical agents from reaching the susceptible material or element or with products or additives applied to the same material.

Once corrected the cause, the defect can be repaired in order to return the element to its original appearance and functionality.

The possibilities of action are very varied, as well as the materials and elements that can be affected and the type of injuries that can affect them, which is why this issue will not be addressed in this work.

In any event, particular attention should be paid to the compatibility between existing materials in old buildings and repair materials not to throw away the intentions to prolong their lifetime.

As part of this methodology, more than one solution can be analyzed to reinforce structural elements that will allow the diagnostic team to recommend the best one according to the damage present in each element.

Execution requires skilled labor in conservation work and proper programming of the building's intervention process and or elements. Moreover, it is necessary to have the necessary equipment and tools to carry out the work. 
Particular interest should be given to the materials used during the construction process since, in all cases, the recommendations and experiences of manufacturers or users correspond to the physical and chemical characteristics in which the building, which is the subject of the intervention, is located.

Reinforcement should be carried out from the time the rehabilitation process begins. This phase of works has a major importance as the quality of the final product relies from it [24].

Subsequently, the objective is to evaluate the results achieved in the intervention. It is necessary to pay attention to the compatibility between the original materials and those that were placed during repair, the cure of defects and their causes, etc.

At this stage, it should be verified, in practice, that the diagnosis was accurate and, in its absence, should be returned to the diagnostic phase to correct any errors that put the building or element previously studied at risk again.

After evaluating the results, the maintenance proposal preparation can be defined avoiding the element to achieve high levels of degradation and preventing its good response for exigencies. In this way, a maintenance proposal must accompany any new work project [25].

The most important aspects that any maintenance proposal should consider are the following: periodic visual reviews, periodic replacement of the finishing material, periodic cleaning of surfaces, and drainage elements. In conclusion, maintenance proposals should include all actions aimed at maintaining the integrity of the building.

Finally, everything concerning the intervention carried out in the building should be filed with the competent authorities to be used as a basis for further repair and consultation by professionals for use in other buildings with similar damage or pathological situations.

They also highlight other assessment tools, such as the XENIOS methodology and software, where the building is decomposed into several discrete macro elements corresponding to spaces with different uses and opening hours, such as hotel rooms, restaurants, lobby and bars, swimming pool, kitchen, technical installations and systems such as air treatment and distribution system, heating, cooling, and air conditioning. Each macro element consists of several elements: wall and floor finishing, swimming pool finishing, heating, cooling terminal units, and lighting system, which may vary according to the environment. Highlighting the calculation of energy demand and the assessment of energy and water savings [26].

There are other computer tools, such as TOBUS - A European method and software for office building refurbishment, which is part of a new family of methodologies and multimedia tools for architects and engineers that can be used for a general assessment and diagnosis of the existing condition of offices, an assessment of various renovation scenarios and retrofit and cost of induction works, in the preliminary phases and which complements the work that was initially described [26].

It is also essential to develop a model that allows a comprehensive analysis of building rehabilitation's economic and environmental costs. This objective is achieved through any technician familiar with cost databases, and apply the proposed methodology, development through a robust and replicable model that allows decision making from a double economic and ecological perspective [27].

\section{Preliminary Survey}

A dimensional survey (Survey and 3D modeling of the building, Figure 4) and the project's (Figure 5) verification were carried out. The building presents the following characteristics: a height of $25 \mathrm{~m}$, total floor surface $21,000 \mathrm{~m}^{2}$, and site area $29,150 \mathrm{~m}^{2}$. The structure consists of piles molded in situ, reinforced concrete pillars, angular beams, and reinforced concrete slabs. The elevator and the stairs are made of reinforced concrete. The masonry is made of ceramic brick. The roofs are flat with infiltration slabs. 


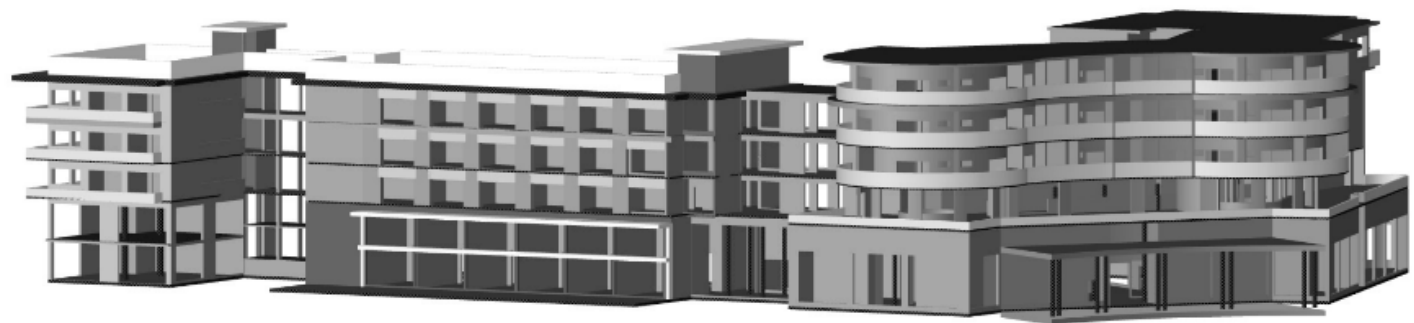

Figure 4. Survey and 3D modeling of the building.

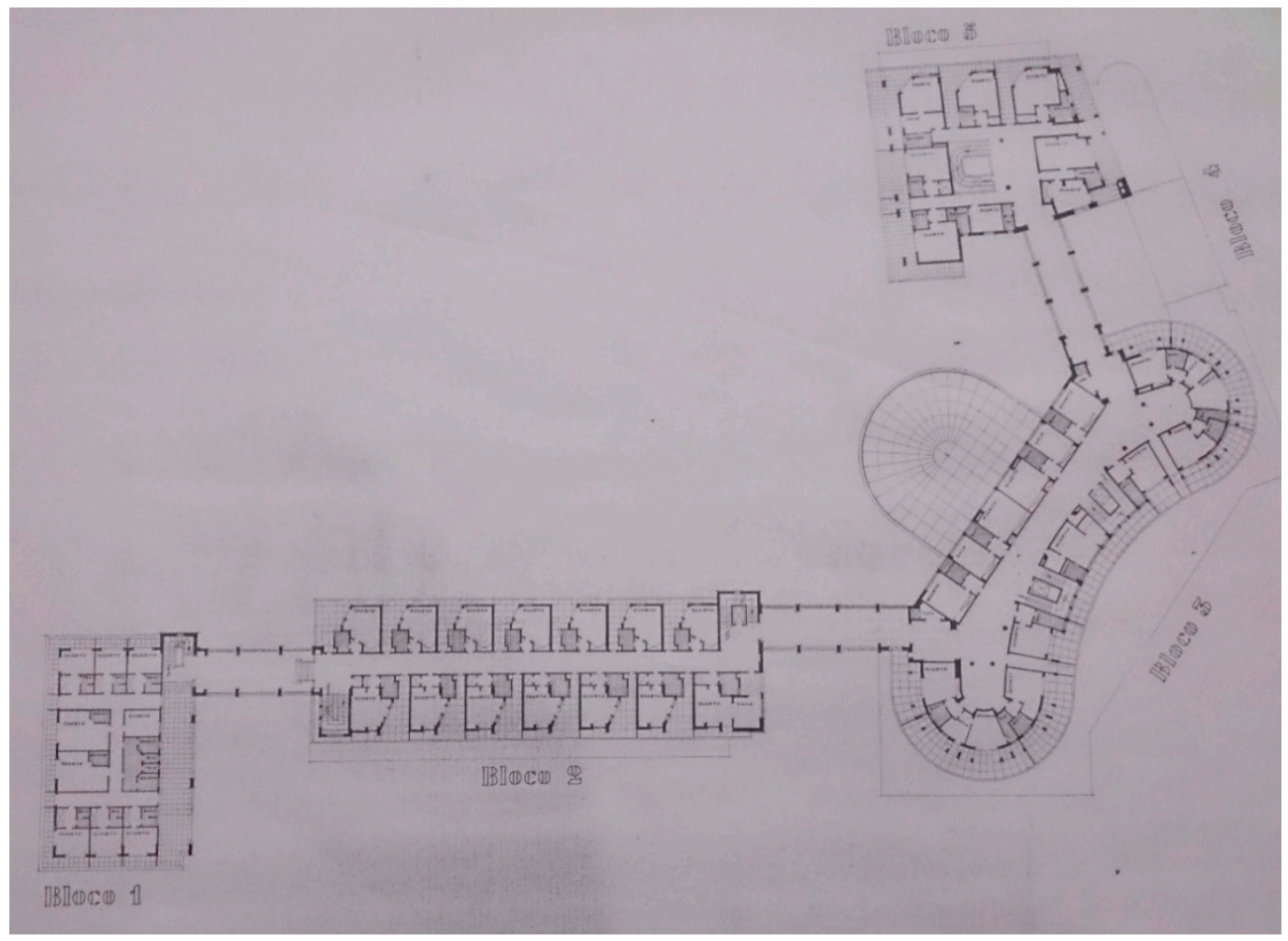

Figure 5. Initial project [9].

During the visual inspection, the most common anomalies in the building were verified and classified. The observation and analysis of pathological symptoms allow making the first diagnosis based on experience, intuition, and observation. Visual inspection is often insufficient but fundamental to design the appropriate diagnostic methodology for the building under study.

The visual inspection of a building, to assess its condition, should include an overview, covering all aspects that may be relevant, such as place of implantation, structure, exterior and interior envelope of the building.

The following Table 1 summarizes the most relevant damages and causes in the visual inspection of the "Grande Hotel", this first analysis allows the evaluation the existing conditions and proposing a diagnostic methodology. 
Table 1. Visual inspection of the "Grande Hotel", Beira, Mozambique.

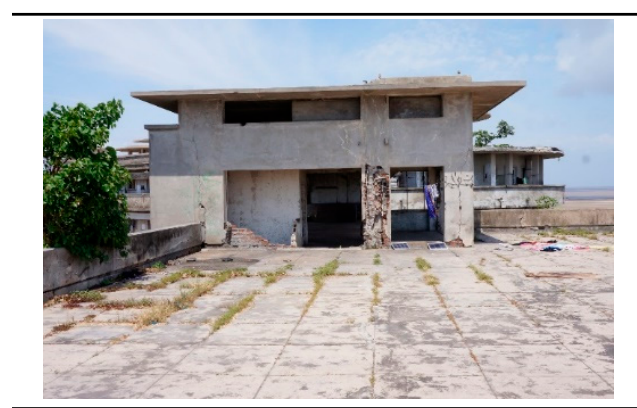

Type of damages: The types of damages that manifest themselves are of mechanical and chemical origin. Regarding mechanical damages, we can observe cracks and, for chemical damages, vegetation growth. These damages are classified as secondary damages.

Causes: For the damages described above, the causes are direct biological (interaction between materials and biological agents that causes vegetation growth), and direct causes, previous damages (obstruction of coverage).

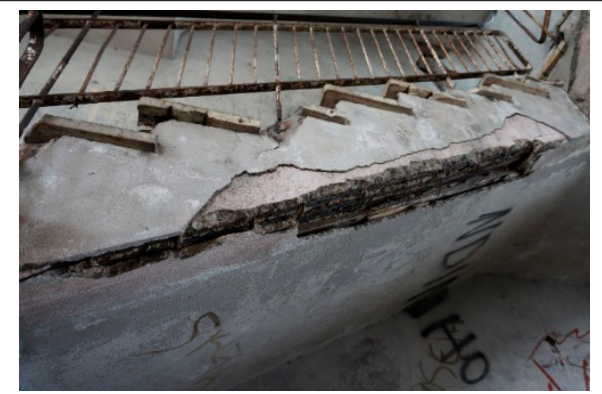

Types of damages: The types of damages that manifest themselves are of mechanical and chemical origin. We can observe the mechanical damage in the figure detachment of concrete and cracks and chemical injuries corrosion of the reinforcement. The damages described are classified as secondary.

Causes: For the damages described above, the causes are mechanical direct, mechanical stresses at the origin of the cracks, and concrete detachment. On the other hand, direct physical causes, exposure to the environment also work.

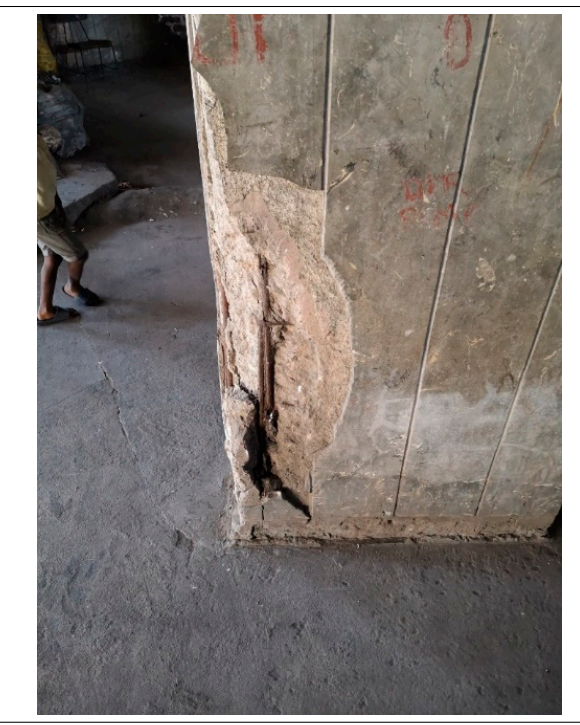

Types of damages: The types of damages that manifest themselves are of mechanical and chemical origin. We can observe the mechanical damage in the figure detachment of concrete and cracks and chemical injuries corrosion of the reinforcement. The damages described are classified as secondary.

Causes: For the damages described above, the causes are direct mechanical, differentiated settlements in the foundations and mechanical stresses at the origin of the concrete cracks and detachment. On the other hand, direct physical causes, exposure to the environment also work.

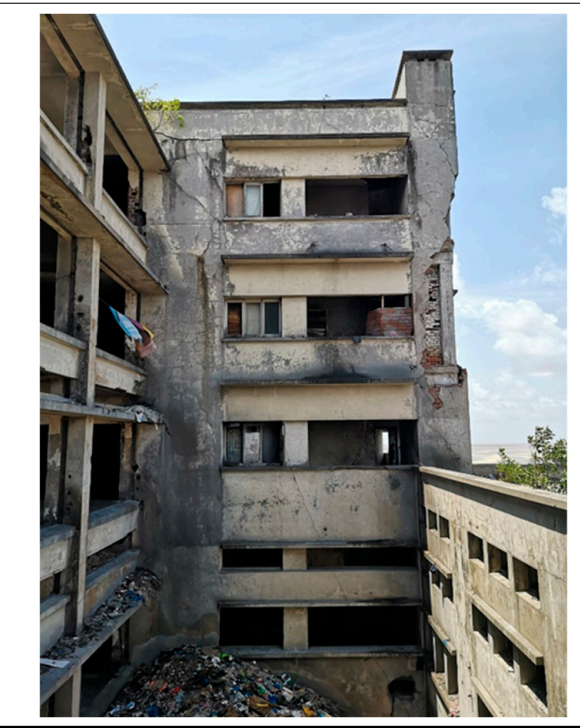

Type of damages: The damages observed in the figure are of chemical, physical, and mechanical origin. For chemical damages, efflorescence's, and plant organisms, i.e., vegetation growth, for physical damages, black spots, greenish spots, and dirt, are observed. And related to mechanical damages, cracks and coating fall is observed. In terms of classification, damages of chemical, mechanical, and physical origin are classified as secondary; only dirt is classified as primary.

Causes: The causes of the damages in the figure on left are, directly, previous damages (moisture by lateral absorption of the waters of the obstructed drainage system that are in some way at the origin of the appearance of efflorescence's, black spots, greenish and dirt, direct mechanical causes (unforeseen mechanical stresses that are causing cracks in the wall region, direct physical causes (temperature variations and retraction of the mortar causing cracks in the facades), and direct biological causes (interaction between biological agents and the materials that propitiate vegetation growth). On the other hand, there are indirect causes of the execution project that may be allied to the appearance of pathologies and inappropriate materials and technologies for solutions. 


\section{Conclusions}

In a building's pathologies intervention process, three well-defined parts can be distinguished: the origin of pathologies, its evolution, and the final aspect. However, the diagnosis method for its study must be crossed inversely (aspect-evolution-origin).

It means that observing the aspect of the pathology is the first step, then the symptom and finally, to reach its origin, to the cause, following its evolution.

This analysis should be methodical and thorough. Therefore, it is necessary to adopt a systematic observation and data collection method and limit possible pre-conceived ideas, i.e., from professional intuition that can be common and useful in some cases but extremely dangerous in others.

Considering the above, a methodology was developed for the diagnosis of buildings whose fundamental premises were as follows: classification and characterization of construction typologies; identification of the damage associated with each constituent element; identification of deterioration in the junction points between the elements; determination of the origin, evolution, and current state of the different pathological states. And the use of specialized software for the detailed assessment, without forgetting an economic, environmental, patrimonial, and social analysis

Main conclusions obtained throughout the research carried out:

- Most buildings in the area under study are affected by pathologies, most of them caused by humidity.

- The most frequent faults that occur due to humidity are those caused by rainwater that seeps through the roof and facade.

- The damages that may appear in a building vary depending on the element where they are located and the building's constituent material.

- Non-destructive testing methods are best suited for application to existing buildings, as they do not affect the tested element's future use. However, sometimes it is necessary to use destructive techniques or tests that are most certainly necessary to assess the structure's component elements' current state.

- Careful analysis is required to select test methods to be applied in a building to assure the more accurate results.

- Visual inspection and the use of pictures is an essential technique for diagnosing any building.

- The essential stages of diagnosis to determine the causes of damage found in a building are background collection, inspection, and testing on-site and laboratory.

Applying an appropriate methodology to diagnose buildings will result in a much more in-depth and objective evaluation of the current state they present.

Author Contributions: Supervision, J.C.G.L.; supervision, A.V.F.; writing-original draft, review and editing, M.M.S. All authors have read and agreed to the published version of the manuscript.

Funding: This research received no external funding.

Institutional Review Board Statement: Not applicable.

Informed Consent Statement: Not applicable.

Data Availability Statement: Not applicable.

Acknowledgments: Beira Municipal Council and the resident community at "Grande Hotel".

Conflicts of Interest: The authors declare no conflict of interest.

\section{References and Notes}

1. Artur, L.; Hilhorst, D. Everyday realities of climate change adaptation in Mozambique. Glob. Environ. Chang. 2012, 22, 529-536. [CrossRef]

2. Forjaz, J.; Lage, L.; Guedes, M.C.; Lopes, L.; Borges, K.E.; Cantuária, G.; Pinheiro, M.D.; Pereira, M.; Lopes, Â.; Aleixo, J.; et al. Arquitectura Sustentável em Moçambique: Manual de Boas Práticas; CPLP Comunidade dos Países de Língua Portuguesa: Lisboa, Portugal, 2011. 
3. Cheer, J.M.; Reeves, K. Colonial heritage and tourism: Ethnic landscape perspectives. J. Herit. Tour. 2015, 10, 151-166. [CrossRef]

4. Sarmento, J.; Linehan, D. The Colonial Hotel: Spacing violence at the Grande Hotel, Beira, Mozambique. Environ. Plan. D Soc. Space 2019, 37, 276-293. [CrossRef]

5. Ornelas, C.; Guedes, J.M.; Sousa, F.; Breda-Vázquez, I. Supporting Residential Built Heritage Rehabilitation through an Integrated Assessment. Int. J. Arch. Herit. 2020, 3058, 1-14. [CrossRef]

6. Mendes, R.P. O modernismo e suas abordagens em Moçambique e Angola. Urbe. Revista Brasileira Gestão Urbana 2012 , 4, 245. [CrossRef]

7. Anonymous. The Delagoa Bay Review. Available online: https://delagoabayword.wordpress.com/2011/02/17/a-beira-e-ogrande-hotel-da-beira/ (accessed on 20 September 2020).

8. Newitt, M. A History of Mozambique; Indian University Press: Boomington, India, 1995.

9. Ivo, F. Estudo Preliminar Para a Desocupação e Demolição Do Grande Hotel na Beira, Beira, Mozambique, 2008.

10. Stoops, L. Grande Hotel [documentary]; Serendipity Films: St. Antelinks, Belgium, 2011.

11. Spinuzza, G. O ciclo do Grande Hotel da Beira: Os documentários Grande Hotel, de Lotte Stoops; Grande Hotel, de Anabela Saint-Maurice; Hóspedes da Noite, de Licínio Azevedo e Amanhecer a andar, de Sílvia Firmino. Remat de Males 2018, 38, 161-185. [CrossRef]

12. Mate, J.C.D.O.M. Construction History and the History of Construction Cultures: Between Architecture and Engineering in Portugal. Buildings 2020, 10, 65. [CrossRef]

13. Arlotta, A.I. Locating heritage value in building material reuse. J. Cult. Herit. Manag. Sustain. Dev. 2019, 10, 6-15. [CrossRef]

14. Mateus da Silva, C.D. Arquitetura Moderna na África Lusófona. Quelimane e a obra de João Garizo do Carmo (1952-1970); IST: Lisboa, Portugal, 2013.

15. Cóias, V. Inspeções e Ensaios na Reabilitação de Edifícios; IST PRESS: Lisboa, Portugal, 2006.

16. Ferreira, A.A. Técnicas de Diagnóstico de Patologias em Edifícios; Faculdade de Engenharia da Universidade do Porto: Porto, Portugal, 2010.

17. Habraken, N. De Dragers en de Mensen: Het Einde van de Massawoningbouw; Scheltema \& Holkema: Amsterdam, The Netherlands, 1961.

18. Farahani, A.; Wallbaum, H.; Dalenbäck, J.-O. Optimized maintenance and renovation scheduling in multifamily buildingsA systematic approach based on condition state and life cycle cost of building components. Constr. Manag. Econ. 2019, 37, 139-155. [CrossRef]

19. Cuperus, Y. An Introduction to Open Building. In Proceedings of the 9th Annual Conference of the International Group for Lean Construction, Singapore, 6-8 August 2001. Available online: http://iglc.net/Papers/Details/137/pdf (accessed on 20 September 2020).

20. Riggio, M.; D'Ayala, D.; A Parisi, M.; Tardini, C. Assessment of heritage timber structures: Review of standards, guidelines and procedures. J. Cult. Herit. 2018, 31, 220-235. [CrossRef]

21. Mehani, Y.; Benouar, D.; Bechtoula, H.; Kibboua, A. Vulnerability evaluation of the strategic buildings in Algiers (Algeria): A methodology. Nat. Hazards 2011, 59, 529-551. [CrossRef]

22. Open Building Implementation. Open Building Implementation, CIB W104. 2006. Available online: http:/ / www.open-building. org /\%5Cnhttp:/ / www.open-building.org/site/map.html (accessed on 20 September 2020).

23. Gonçalves, J.; Mateus, R.; Silvestre, J.D. Comparative analysis of inspection and diagnosis tools for ancient buildings. In Digital Heritage. Progress in Cultural Heritage: Documentation, Preservation, and Protection; Springer: Cham, Switzerland, 2018; Volume 11197, pp. 289-298. [CrossRef]

24. Balaras, C.A.; Droutsa, K.; Dascalaki, E.; Kontoyiannidis, S. Deterioration of European apartment buildings. Energy Build. 2005, 37, 515-527. [CrossRef]

25. Dascalaki, E.; Balaras, C.A. XENIOS-A methodology for assessing refurbishment scenarios and the potential of application of RES and RUE in hotels. Energy Build. 2004, 36, 1091-1105. [CrossRef]

26. Balaras, C.A. TOBUS-A European method and software for office building refurbishment. Energy Build. 2002, 34, 111-112. [CrossRef]

27. Alba-Rodríguez, M.D.; Martínez-Rocamora, A.; González-Vallejo, P.; Ferreira-Sánchez, A.; Marrero, M. Building rehabilitation versus demolition and new construction: Economic and environmental assessment. Environ. Impact Assess. Rev. 2017, 66, 115-126. [CrossRef] 